\title{
SERBEST BASINÇ DAYANIMININ TAHMININDE SUGENO BULANIK MANTIK YAKLAŞIMI
}

\author{
Eray YILDIRIM \\ Eyübhan AVCI \\ Bahadir YILMAZ
}

Alınma: 17.01.2021; düzeltme: 18.02.2021; kabul: 01.04.2021

Öz: Bu çalışmanın amacı ince taneli çimento ile enjeksiyon yapılmış kum zeminlerin serbest basınç dayanımı değerinin Sugeno bulanık çıkarım sistemiyle tahmin edilmesi ve regresyon yöntemleriyle (doğrusal ve doğrusal olmayan) elde edilen tahmin sonuçlarıyla karşılaştırılmasıdır. Regresyon analizi için dört farklı denklem (doğrusal, polinom, üstel ve eksponansiyel fonksiyonlar) kullanılmıștır. Buna göre serbest basınç dayanımının tahminine yönelik olarak toplam 5 model oluşturulmuştur. Girdi parametresi olarak enjeksiyon basıncı değerleri çıktı parametresi (tahmin edilen parametre) olarak ise serbest basınç dayanım değerleri kullanılmıştır. Sugeno bulanık mantık (Sugeno BM) yöntemi oluşturulurken girdi parametresi için 7 üyelik fonksiyonu tanımlanmış, çıktı üyelik fonksiyonları ise lineer olarak alınmıştır. Modellerin tahmin performansını ölçmek amacıyla determinasyon katsayısı $\left(\mathrm{R}^{2}\right)$ ve Ortalama Karesel Hata $(\mathrm{OKH})$ ölçütleri kullanılmıştır. Hesaplanan $\mathrm{R}^{2}$ ve $\mathrm{OKH}$ değerlerine göre geliştirilen modellerin ince taneli çimento ile enjeksiyon yapılmış kum zeminlerin serbest basınç dayanım değerlerini tahmin etmede oldukça iyi sonuçlar verdiği görülmüştür. Modellerin tahmin performanslarına göre başarı sıralaması Sugeno BM modeli, polinom, doğrusal, üstel ve eksponansiyel denklemleri ile oluşturulan regresyon modelleri şeklindedir. Sugeno BM yöntemi, insanın düşünme mekanizmasına, çıkarım ve karar verme sistemine yakın olduğundan dolayı anlaşılmasının kolay olması bir avantaj sağlamaktadır. Sugeno BM yönteminin avantajları ve geliştirilen Sugeno BM modelinin tahmin başarısından dolayı regresyon yöntemine alternatif olabileceği görülmüştür.

Anahtar Kelimeler: Sugeno bulanık mantık, Serbest basınç dayanımı, İnce taneli çimento, Enjeksiyon

\section{Sugeno Fuzzy Logic Approach to Estimating Unconfined Compressive Strength}

\begin{abstract}
The aim of this study is to predict the unconfined compressive strength of sand grouted with ultrafine cement using the Sugeno fuzzy inference system and to compare the results with the predictions obtained by the regression models (linear and non-linear). Four types of regression models namely linear, polynomial, power, and exponential are used in the analyses. Injection pressure values are used as input parameters while unconfined compressive strength values are used as output parameters. Seven membership functions for the input parameter and linear functions for the output parameter are assigned for Sugeno fuzzy inference system. To evaluate the accuracy of the models, coefficient of determination $\left(\mathrm{R}^{2}\right)$ and mean squared error (MSE) are used. Based on the calculated $\mathrm{R}^{2}$ and MSE values, it is observed that the developed models reveal good results in predicting the strength of sand grouted with ultrafine cement. According to the performance of the models, Sugeno fuzzy logic, polynomial, linear, power, and exponential regression models have the most successive predictions, respectively. Sugeno fuzzy logic provides an advantage due to easy to understand and similar mechanism with the human thinking, inference, and decision-making systems. It has been observed that the Sugeno fuzzy logic model can be an alternative to the regression method due to the advantages and the successive prediction.
\end{abstract}

Keywords: Sugeno fuzzy logic, Unconfined compressive strength, Microfine cement, Grouting

\footnotetext{
* Bursa Teknik Üniversitesi, Mühendislik ve Doğa Bilimleri Fakültesi, İnşaat Müh. Bölümü, 16330, Bursa/Türkiye İletişim Yazarı: Eray YILDIRIM (eray.yildirim@btu.edu.tr)
} 


\section{GİRIŞ}

Enjeksiyon, enjeksiyon malzemesinin basınç altında zemin içindeki boşluklara enjekte edilmesi işlemi olup ilk kez Fransız mühendis Charles Berigny (1802) tarafindan Dieppe limanındaki ahşap kazıkların erozyonundan kaynaklanan sorunu çözmek için kil ve puzolan harcını zemine enjekte etmesiyle başlamıştır (Nonlevier, 1989). 1932 yılında Colorado Nehri üzerinde yapılan Hoover barajında ve 1934 yılında Fransa'da yapılan Chavanon Barajı'nda ise ilk baraj enjeksiyon uygulamaları yapılmıştır (Karol, 2003). Joosten (1926) tarafindan kumlara ilk kez çimento ve kimyasal enjeksiyon uygulamaları yapılmaya başlanmıştır ve 20. yy sonlarına doğru Joosten tekniği olarak tanımlanan uygulama yaygınlaşmıştır (Karol, 2003). Enjeksiyon uygulamalarının başlıca amaçları; zeminlerin taşıma kapasitelerini arttırmak, zeminlerin oturmalarını azaltmak, farklı oturma yapmış temelleri kaldırmak, sıvılaşabilir zeminlerin sıvılaşma potansiyellerini önlemek, tünel kazılarında stabiliteyi sağlamak, zeminde geçirimsiz yüzeyler oluşturmak, yeraltı suyunu kontrol altına almak, kazı ve şevlerin stabilitelerini sağlamaktır (Rawlings ve diğ., 2000).

Permeasyon enjeksiyonu, enjeksiyon uygulamaları içinde en yaygın kullanılan enjeksiyon tekniklerinden biri olup düşük viskoziteye sahip enjeksiyon malzemesinin, düşük basınçlar altında $(\leq 0,5 \mathrm{MPa})$, zemin içindeki boşluklara zeminde herhangi bir öteleme veya hidrolik kırılma (örseleme) yapmadan enjekte edilmesi işlemi olarak tanımlanmaktadır (Rawlings ve diğ., 2000). Zemin içindeki boşluklara enjekte edilen enjeksiyon malzemesi zamanla sertleşerek zeminin dayanımını arttırmakta ve geçirimlilik özelliklerini azaltmaktadır. Permeasyon enjeksiyonu uygulamalarında Portland Çimentoları yaygın olarak kullanılmakta olup yüksek partikül boyutları $(100 \mu \mathrm{m})$ nedeniyle iri kum boyutunda zeminlere kadar enjekte edilebilmişlerdir. Portland çimentosunun ince ve orta kumlara penetre olamamasından dolayı kimyasal enjeksiyon uygulamaları yaygınlaşmıştır. 1980 yılından sonra bazı kimyasal enjeksiyonların çevrede yarattıkları olumsuz etkiler ve çevrede toksik etki yaratmaları sebebiyle kullanımlarına kısıtlamalar getirilmiştir. Portland çimentolarının partikül boyutlarının küçültülmesi ile ortaya ince taneli çimentolar çıkmıştır. İnce taneli çimentolar tane çapı $20 \mu \mathrm{m}$ den küçük ve özgül ağrılığ $800 \mathrm{~m}^{2} / \mathrm{kg}$ ' dan büyük olan çimentolar olarak tanımlanmaktadır (Shroff ve Shah, 1999). İnce taneli çimento ile yapılan enjeksiyon çalışmalarında ince kum boyutuna kadar enjeksiyon yapılabilmiştir (Perret ve diğ., 2000). İnce taneli çimentolar ile yapılan enjeksiyon çalışmalarında zeminin dayanımlarının oldukça arttığı ve geçirimlilik değerlerinin azaldığı görülmektedir (Markou ve Droudakis, 2013; Schwarz ve Krizek, 1994; Chritodoulou ve diğ., 2009; Hashimoto ve diğ., 2016; Chen ve diğ., 2018; Avci, 2019; Jaforpour ve diğ., 2020).

Bulanık mantık yöntemi, birçok disiplinde olduğu gibi geoteknik alanında da ilgi uyandırmakta ve özellikle son yıllarda bu çalışmalarda artış görülmektedir. Bulanık mantık yöntemi ile ilgili geoteknik alanında çeşitli konularında çalışmalar bulunmaktadır. Yıldırım ve diğ. (2007), bulanık mantık yöntemini kullanarak AASHTO zemin sınıflama sisteminin kullanımı için bir model önermişlerdir. Önerilen modelde elek analizi sonuçlarını, likit limit, plastisite indisi ve grup indisi değerlerini girdi olarak, AASHTO zemin sınıfını ise çıktı olarak tanımlanmıştır. Modelin oluşturulmasında üçgen üyelik fonksiyonları kullanılmıştır. Bulanık mantık ile elde edilen sonuçlar gerçek sonuçlar ile karşılaştıııldığında aynı zemin tanımlamalarının elde edildiği görülmektedir. Yıldırım ve diğ. (2007), SPT-N verilerini kullanarak YSA (Yapay Sinir Ağları) ve Sugeno bulanık mantık yöntemleriyle kayma dalgası hızı kestirimi yapmışlardır. Sugeno bulanık mantık yönteminde girdiler üçgen üyelik fonksiyonu ile tanımlanırken çıktı değeri lineer fonksiyon olarak tanımlanmıştır. Her iki model karşılaştırıldığında Sugeno bulanık mantık yönteminin daha iyi performans gösterdiği görülmektedir. Arbabsiar ve diğg. (2020), bulanık mantık yöntemini kullanarak tünel açma makinesinin ilerleme oranının tahmin edilmesi ve geoteknik risk seviyesinin belirlenmesine yönelik model oluşturmuşlardır. Sujatha ve diğ. (2020), zemin indeks özelliklerini (partikül boyutları, likit limit, plastik limit ve plastisite indisi) 
kullanarak bulanık mantık yöntemiyle zemin sınıflaması modeli geliştirmişlerdir. Sünbül ve diğ. (2015), bulanık mantık yöntemiyle sıvılaşma riskine iliş̧in bir model geliştirmiş̧lerdir. Bu modelde yeraltı su seviyesi ve kil içeriği (\%) girdi olarak sıvılaşma riski ise çıtı olarak kullanılmıştır. Dhanasekar ve Rajakumar (2018) bulanık mantık yöntemini kullanarak yol stabilizasyon malzemesinin etkinliğinin belirlenmesi üzerine model oluşturmuşlardır. Bu modelde likit limit, plastik limit, plastisite indisi, maksimum kuru ağırlık ve optimum su muhtevası değerleri girdi olarak kullanılmıştır. Bu girdi değerlerini kullanarak serbest basınç dayanımı, CBR (California Bearing Ratio) ve elastisite modülü değerlerinin tahmini yapılmıştır. Önerilen bulanık mantık modeli ile yol dayanıklılığı ve güvenirliği ile ilgili olumlu sonuçlar elde etmişlerdir. Mishra ve Basu (2013) kayaçlanın tek eksenli basınç dayanımı değerinin tahmini için bulanık çıkarım sistemi ve regresyon analizini kullanmışlardır. Bu amaca yönelik olarak nokta yük dayanımı, disk makaslama indeksi, Schmidt çekiç ölçümleri ve ultrasonik P dalgası hızlarını girdi olarak kullanarak tek eksenli serbest basınç dayanım değerlerini bulanık mantık yöntemi ile tahmin etmişlerdir. Zorluer ve diğ. (2010), kil dispersitibiletisinin belirlenmesi amaciyla bulanık mantık yaklaşımı kullanmışlardır. İğne deliği, çifte hidrometre, Na (\%)-TDS ve ESP-CEC deney sonuçları kullanılarak bulanık kümeler oluşturulmuş ve dispertibilite tahminleri yapılmıştır. Bulanık mantık tekniği ile 29 örneğin dispersibilitisi incelenmiş ve daha güvenilir objektif sonuçlar verdiği görülmüştür. Bulanık mantık yönteminin kullanımı özellikle son yıllarda oldukça artmıştır. Yöntemin gelecek zamanlarda çok daha yaygın olarak kullanılacağı öngörülmektedir. Yöntem birç̧ok farklı disiplinde kullanılmakta ve ilgi odağı olan konular arasındadır. Özellikle deneysel çalışmalarda veriler arasındaki ilişkinin belirlenmesi ve deney sonuçlarının tahmin edilmesinde oldukça iyi sonuçlar verdiği görülmektedir. Bu çalışmada ince taneli çimento ile enjeksiyon yapılmış kum zeminlerin serbest basınç dayanımlarının tahmininde Sugeno bulanık mantık çıkarım sisteminin kullanılabilirliği incelenmiştir.

\section{DENEYSEL ÇALIŞMALAR VE VERILERIN ELDE EDÍLMESİ}

Yapılan enjeksiyon çalışmalarında kuvars kumu kullanılmıştır. Elde edilen kum zeminler ilk önce elekler yardımıla (ASTM elekleri) ince kum ve orta kum olmak üzere iki alt gruba ayrılmıştır. 10 nolu elekten geçen ve 40 nolu elek üzerinde kalan zeminler orta kum, 40 nolu elekten geçen ve 200 nolu elek üzerinde kalan zeminler ince kum olarak gruplandırılmıştır. Daha sonra ince ve orta kum zeminler farklı ağılık oranlarında karıştırılarak 11 farklı dane dağılımı oluşturulmuştur (Tablo 1).

Tablo 1. Enjeksiyon deneylerinde kullanılan kum karışım oranları

\begin{tabular}{|c|cc|}
\hline \multirow{2}{*}{$\begin{array}{c}\text { Numune } \\
\text { No }\end{array}$} & \multicolumn{2}{|c|}{ Kum Oran $1 \%$} \\
\cline { 2 - 3 } & İnce & Orta \\
\hline 1 & 100 & 0 \\
2 & 90 & 10 \\
3 & 80 & 20 \\
4 & 70 & 30 \\
5 & 60 & 40 \\
6 & 50 & 50 \\
7 & 40 & 60 \\
8 & 30 & 70 \\
9 & 20 & 80 \\
10 & 10 & 90 \\
11 & 0 & 100 \\
\hline
\end{tabular}

Enjeksiyon deneyleri Tablo 1'de görülen farklı dane dağılımlarındaki kum zeminlere yapılmıştır. Enjeksiyon deneylerinde ince taneli çimento olarak Spinor A6 ve Ultrafine 12 ince taneli çimentoları kullanılmıştır. Enjeksiyon işlemlerini gerçekleştirmek için özel tasarlanmış 
deney düzeneği kullanılmıştır (Şekil 1a). Enjeksiyon deney düzeneğinde enjeksiyon ekipmanları olarak enjeksiyon masası, enjeksiyon kalıbı, kompressör, enjeksiyon tank1, ara bağlantı elemanı ve basınç ölçer (manometre) bulunmaktadır. Kalıp içine zeminler 3 tabaka halinde yerleştirilmiştir. Hazırlanmış kalıplar enjeksiyon deney düzeneğine yerleştirildikten sonra enjeksiyon deneyleri yapılmıştır. Enjeksiyon deneylerinde başarılı olan numuneler priz süreleri tamamlanıncaya kadar kalıplarda bekletilmiş, priz süreleri tamamlandıktan sonra kalıplardan çıkartılarak kür tankına yerleştirilmiş̧ir. 150. gün sonunda numuneler kür tankından çıkartılarak numunelere serbest basınç deneyleri (ASTM D4219-02) yapılmıştır (Şekil 1b).
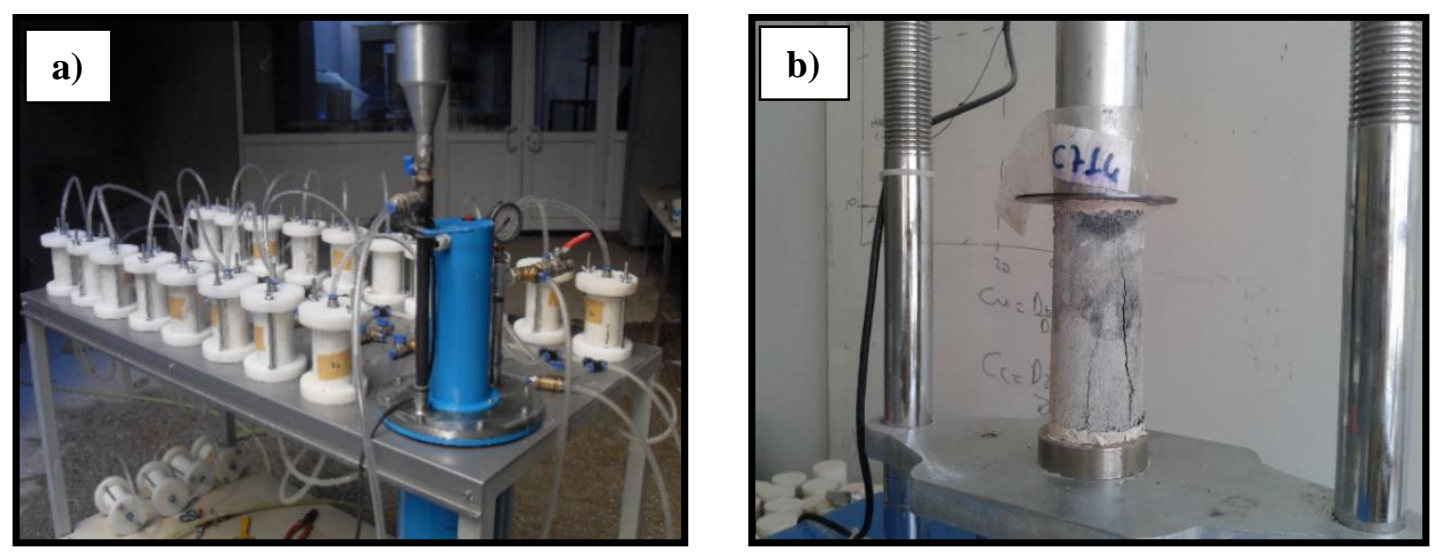

Şekil 1:

a) Enjeksiyon deney düzeneği b) Serbest basınç deney uygulaması

\section{SUGENO BULANIK ÇIKARIM SISTEMI}

Bulanık mantık (Fuzzy Logic) yapay zekanın (Artificial Intelligence, AI) bir tekniği olup 1965 yılında Zadeh L.A. tarafından geliştirilmiştir. Bulanık mantık yöntemi özellikle kesin sayısal değerler içermeyen problemlerin modellenmesinde klasik mantığa göre daha kullanışlı ve kolay modelleme imkânı sağlamaktadır. Klasik mantık (iki değerli mantık) bilgisayar diline daha yatkın olup herhangi bir durum için kesin bir girdi ve kesin bir cevabı (dolu veya boş, 1 veya 0 gibi) bulunmaktadır. Bulanık mantık ise insan düşence biçimine daha uygundur. Zadeh (1965) insan düşünme biçimini dilsel ifadeler ile (gri, zayıf, yüksek, 1lık gibi) dereceli bir biçimde tanımlayarak matematiksel formülasyon geliştirmiştir (Zadeh, 1965). Dilsel ifadelerin kullanımı, bulanık mantığın en önemli özelliği olup farklılığını göstermektedir. Bulanık mantık yöntemi insan düşünce sistemine yakın olduğu için uygulaması kolaydır. Özellikle doğrusal olmayan (nonlinear) problemlerin modellenmesinde kullanılabilmektedir. Bulanık mantık yönteminin uygulanmasında, üyelik fonksiyonlarının ve kurallarının oluşturulmasında uzman kişilerin tecrübe, bilgi ve deneyimlerinin kullanılması gerekmektedir (Elmas, 2011).

Bulanık mantık temel yapısı, bulanıklaştırma, kural tabanı, çıkarım ve durulaştırma bileşenlerinden oluşmaktadır. Şekil 2'de bu bileşenlerden oluşan Bulanık Mantık yönteminin temel çalışma mekanizması görülmektedir.

Bulanık mantık da girdilerden çıktının elde edilmesine yönelik çeşitli metotlar, çıkarım sistemleri bulunmaktadır. Bu çıkarım sistemlerinden en çok kullanılanlar Mamdani ve Sugeno çıkarım sistemleridir. 1975 yılında Mamdani tarafindan geliştirilen Mamdani çıkarım sistemi, insan algısına uygun, modellenmesi ve yorumlanabilirliği kolaydır. 1985 yılında Takagi ve Sugeno tarafından geliştirilen Sugeno (yada Takagi-Sugeno) çıkarım sistemi ise özellikle matematiksel analiz, hesaplama için çok uygun olup sayısal kesin sonuç vermektedir (Takagi ve Sugeno, 1985). 


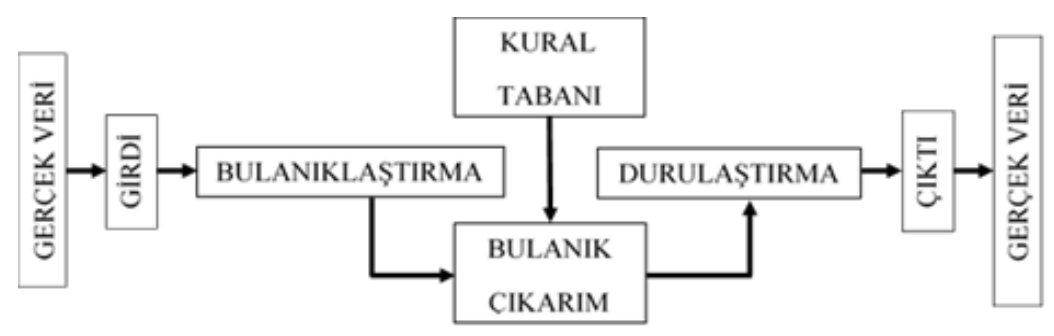

Şekil 2:

Bulanık Mantık yönteminin temel çalışma mekanizması

Bir bulanık mantık modelinin oluşturulmasında ilk olarak girdi parametreleri için üyelik fonksiyonları belirlenerek bulanıklaştırma işlemi gerçekleştirilir. Daha sonra probleme uygun kural tabanı oluşturulmaktadır. Kurallar belirlendikten sonra seçilen çıkarım sistemi uygulanarak bulanık sonuçlar elde edilir. En son işlem olarak durulaştırma yapılarak gerçek sonuçlar elde edilir. Şekil 3'de bu çalışmada kullanılan Sugeno çıkarım sisteminin işleyiş ve matematiksel sistemi görülmektedir. Sugeno çıkarım sisteminde Mamdani çıkarım yönteminden farklı olarak çıktı üyelik fonksiyonlarının sabit veya lineer olmasıdır. Sugeno çıkarım sisteminde çıktılar girdilerin fonksiyonundan oluşmaktadır.

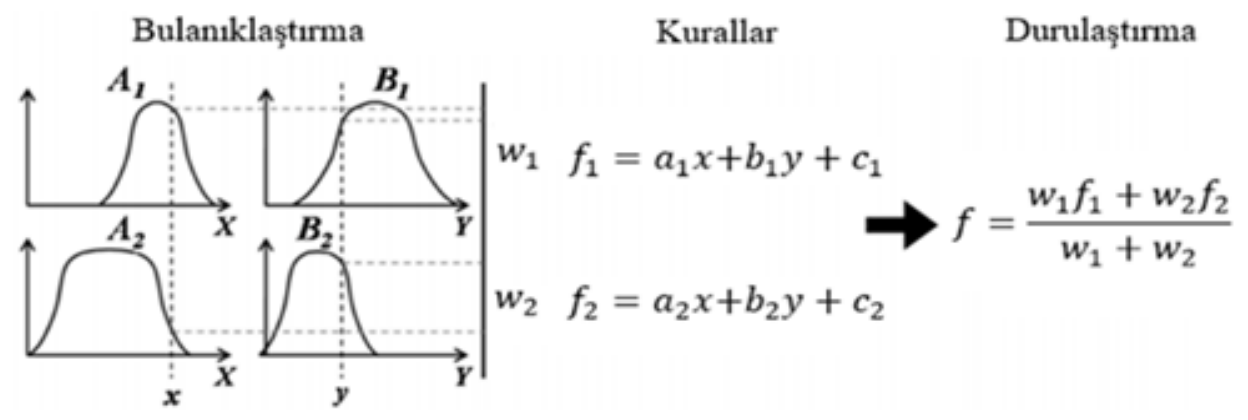

Şekil 3:

Sugeno bulanık çıkarım sistemi (Cho ve diğ., 2020)

Sugeno bulanık çıkarım sisteminde kurallar aşağıdaki gibi gösterilebilir.

Kural 1: Eğer $x, A_{1}$ ve $y, B_{1}$, ise $z, f_{1}(x, y)=a_{1} x+b_{1} y+c_{1}$

Kural 2: Eğer $x, A_{2}$ ve $y, B_{2}$, ise $z, f_{2}(x, y)=a_{2} x+b_{2} y+c_{2}$

Şekil 3'de ve kurallarda belirtilen $\mathrm{x}$ ve y girdi değerlerini, A ve B ise $\mathrm{x}$ ve y girdileri için bulanık kümeleri ifade etmektedir. f kurallar, a, b ve c katsayı (en küçük kareler metodu ile elde edilebilir) ve $\mathrm{w}$ ise üyelik derecesini ifade etmektedir. Durulaştırma aşamasında genellikle ağırlıklı ortalama yöntemi kullanılarak sonuç elde edilmektedir.

\section{UYGULAMA VE BULGULAR}

Enjeksiyon deneylerinde başarılı olmuş numuneler kalıplardan çıkartılmış ve 150 gün boyunca kür koşullarında bekletilmiştir. 150 gün sonunda numuneler kür tankından alınarak serbest basınç deneyleri yapılmıştır. Daha sonra enjeksiyon basıncı değeri ile serbest basınç değeri arasındaki ilişki regresyon ve Sugeno bulanık mantık yöntemleri ile incelenmiştir. Enjeksiyon basıncı değerleri girdi (açıklayıcı veya bağımsız), Serbest basınç dayanımını değerleri ise tahmin edilen çıktı olarak alınmıştır. Deney sonuçlarından elde edilen enjeksiyon basınç değeri ve serbest basınç değerlerinden oluşan toplam 427 veri çifti kullanılmıştır (Şekil 4). Deneylerden elde edilen 
enjeksiyon basıncı değerleri $10 \mathrm{kPa}-545 \mathrm{kPa}$ arasında, serbest basınç dayanımı değerleri ise 1,82 $\mathrm{MPa}-23,88 \mathrm{MPa}$ arasında değişmektedir.

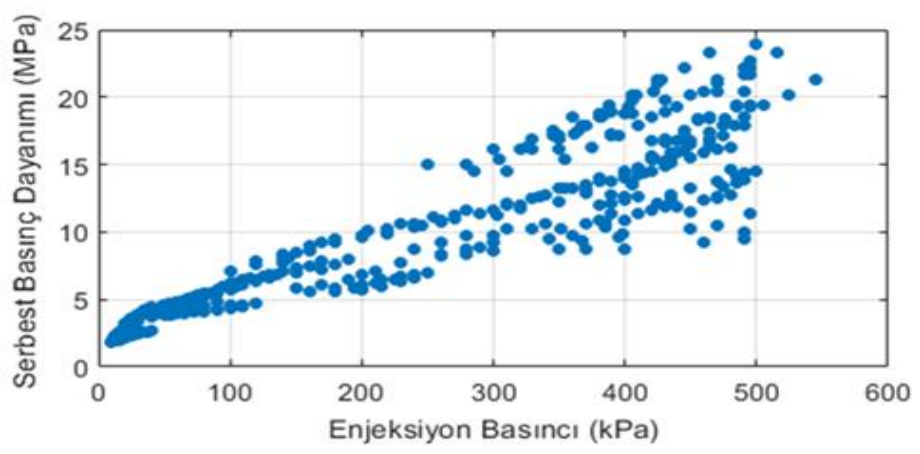

Şekil 4:

Verilerin Dă̆ılım grafiği

Şekil 4' de görüleceği üzere deneyler sonucunda elde edilen serbest basınç dayanımı değerleri saçılım göstermektedir. Elde edilen grafik yorumlanabilir olmasına karşın matematiksel bir fonksiyon ile tanımlanması mümkün görülmemektedir. Sugeno BM ve regresyon denklemleri kullanılarak veriler arasındaki ilişki matematiksel olarak tanımlanmaya çalışılımıştır. Elde edilen tahmin modelleri kullanılarak çalışmadaki sınırlar içindeki herhangi bir enjeksiyon basıncı değeri için serbest basınç dayanımı değerinin ön kestirimi mümkün olacaktır. Bu durum gerçekte ölçülen serbest basınç dayanım değerlerinin bir kontrolünü sağlamamızda yardımcı olacaktır. Ayrıca tahminler deney yapılmamış veya yapılamamış durumlar için fikir vermek amacıyla kullanılabilir.

Regresyon analizi, verilerin (bağımlı ve bağımsız değişkenler) birbirleri ile olan ilişkilerinin incelenmesinde oldukça sıklıkla kullanılan yöntemlerin başında gelmektedir. Bu yöntemde en küçük kareler tekniği uygulanarak en uygun denklem elde edilmeye çalış1lır. Regresyon analizinde gerçek ve tahmin edilen değerleri kullanarak determinasyon katsayısı $\left(\mathrm{R}^{2}\right)$ hesaplanmaktadır. $\mathrm{R}^{2}$ değeri regresyon modelinin başarısını göstermektedir. Bu değer $0-1$ arasında değişmektedir. Değerin 1 veya 1'e yakın olması tahmin başarısının yüksek, 0 veya 0 'a yakın olması tahmin başarısının düşük olduğunu göstermektedir. Bağımlı değişken (tahmin edilen değiş̧ken) ve bağımsız değişken/değişkenler (açıklayıcı değişken) arasındaki ilişki doğrusal (linear) ve/veya doğrusal olmayan (non-linear) regresyon analizleri kullanılarak incelenebilmektedir. Bu çalışmada veriler arasındaki ilişki hem doğrusal hem de doğrusal olmayan regresyon analizleri ile incelenmiştir. Doğrusal olmayan regresyon analizinde polinom (polynomial), eksponansiyel (exponential) ve üstel (power) denklemler kullanılmıştır. Çalışmada geliştirilen modellerin performansını değerlendirmek için kullanılan diğer bir ölçüt ise Ortalama Karesel Hatadır (OKH, Mean Squared Error, MSE). Ortalama Karesel Hata tahmin için kullanılan modelin performansını değerlendirmek amacıyla en sık kullanılan ölçütlerden birisi olup model ile elde edilen tahminlerin gerçek değerlerle ne derecede örtüştüğünü ölçmemizi sağlamaktadır. Tahmin hatasının büyüklüğünü ve ölçümün duyarlılığını göstermektedir. Modelin tahmin edilen değerleri gerçek değerlere yakın olması durumunda OKH değeri küçülmekte, uzak olması durumunda ise $\mathrm{OKH}$ değeri artmaktadır. OKH değerinin sıfıra yakın olması modelin daha iyi performans gösterdiğini, değerin sıfır olması ise modelin hiç hata yapmadığını göstermektedir. Tablo 2'de regresyon analizinde kullanılan denklemler, denklemlerin katsayıları, determinasyon katsayıları ve Ortalama Karesel Hata değerleri görülmektedir. 
Tablo 2. Serbest basınç dayanımı değerinin tahminde kullanılan regresyon modelleri, modellerin denklemleri, elde edilen katsayılar, $\mathbf{R}^{2}$ değerleri ve OKH değerleri

\begin{tabular}{llllll}
\hline Model & Denklem & Katsaylar & $\mathbf{R}^{2}$ & OKH \\
\hline Doğrusal & $\mathrm{Y}=\mathrm{B}_{0}+\mathrm{B}_{1} \mathrm{X}$ & $\mathrm{B}_{0}=2,249$ & $\mathrm{~B}_{1}=0,0314$ & 0,8259 & 5,93 \\
Polinom & $\mathrm{Y}=\mathrm{B}_{0}+\mathrm{B}_{1} \mathrm{X}+\mathrm{B}_{2} \mathrm{X}^{2}$ & $\mathrm{~B}_{0}=-4,02 \mathrm{e}^{-06} \mathrm{~B}_{1}=0,0334 \mathrm{~B}_{2}=2,115$ & 0,8261 & 5,93 \\
Eksponansiyel & $\mathrm{Y}=\mathrm{B}_{0} \exp ^{\left(\mathrm{B}_{1} \mathrm{X}\right)}$ & $\mathrm{B}_{0}=4,165$ & $\mathrm{~B}_{1}=0,0031$ & 0,7960 & 6,95 \\
Üstel & $\mathrm{Y}=\mathrm{B}_{0} \mathrm{X}^{\mathrm{B}_{1}}$ & $\mathrm{~B}_{0}=0,2251$ & $\mathrm{~B}_{1}=0,6991$ & 0,8209 & 6,10 \\
\hline
\end{tabular}

Şekil 5'de verilere uygulanmış doğrusal ve doğrusal olmayan regresyon analizleri görülmektedir.

a) Doğrusal (Linear)

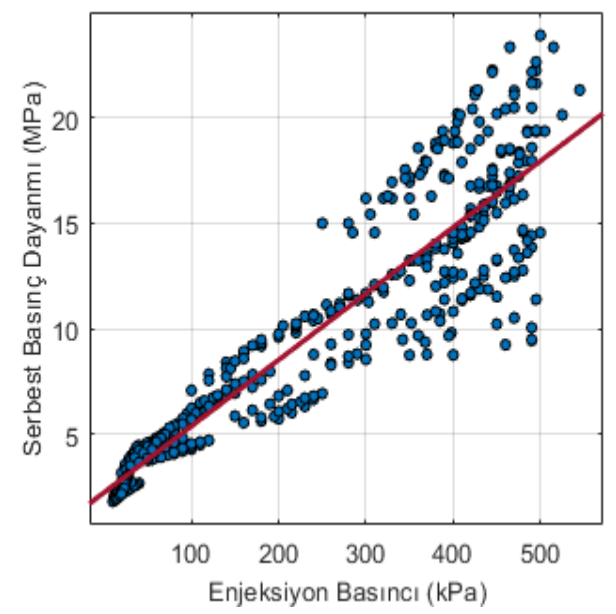

c) Eksponansiyel (Exponential)

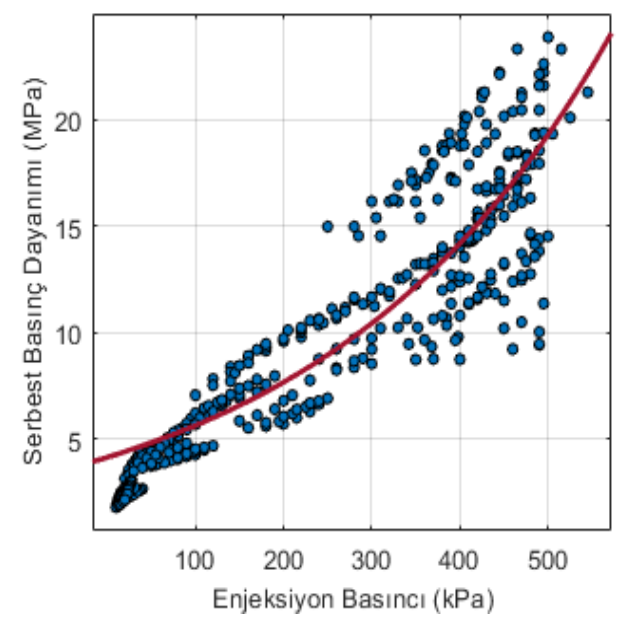

b) Polinom (Polynomial)

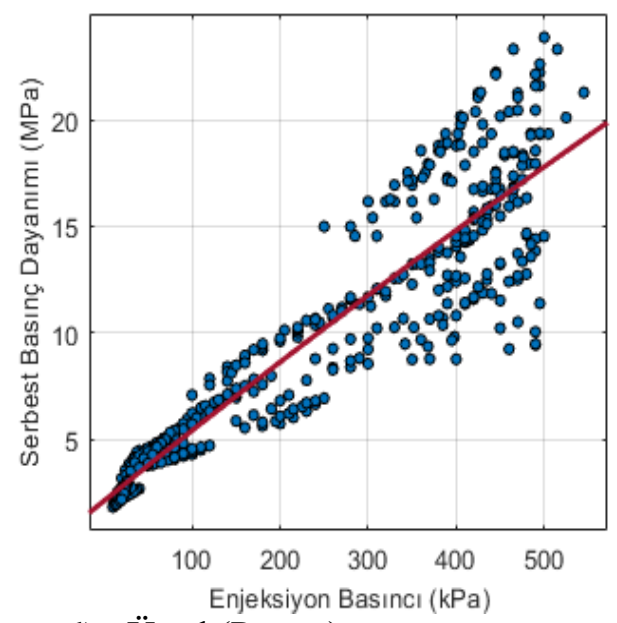

d) Üstel (Power)

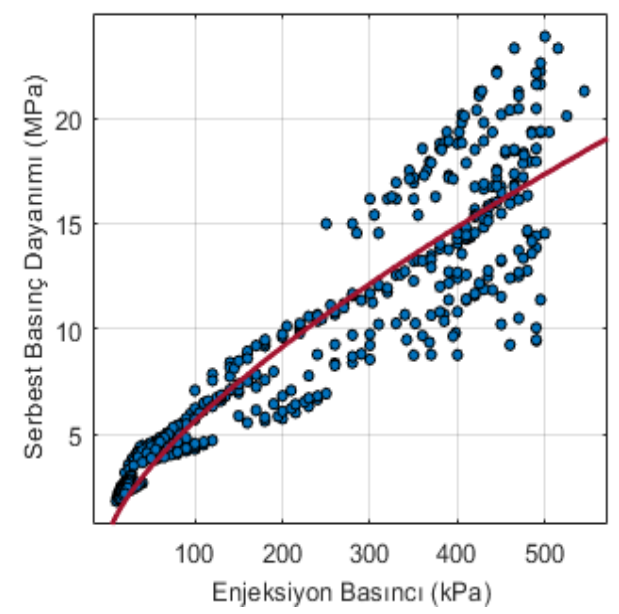

Şekil 5:

Serbest Basınç Dayanımı ( $\mathrm{MPa}$ ) ve Enjesiyon Basıncı (kPa) arasındaki ilişki. a)Doğrusal

(Linear), b) Polinom (Polynomial), c)Eksponansiyel (Exponential) ve d) Üstel (Power) denklemler için uygulanan regresyon analizi. Kırmızı çizgi regresyon eğrisini göstermektedir. 
Şekil 5 ve Tablo 2'de görüleceği üzere doğrusal ve polinomal denklemleri kullanılarak oluşturulan regresyon modelleri kısmen daha iyi sonuç vermektedir. Polinom regresyon modeli kullanılarak elde edilen regresyon eğrisi büyük ölçüde doğrusal karakter göstermektedir. Buna göre regresyon analizini gerçekleştirdiğimiz veri dağılımının doğrusal özellik gösterdiği söylenebilir. Uygulanan regresyon analizlerinde en düşük uyumu eksponansiyel denklem ile oluşturulan regresyon modeli göstermektedir.

$\mathrm{Bu}$ çalışmada kestirim problemlerinde oldukça sık kullanılan regresyon analizine alternatif olarak Sugeno bulanık mantık yöntemi kullanılarak bir model oluşturulmuştur. Şekil 6'da Sugeno bulanık mantık modelinin şematik gösterimi görülmektedir. Regresyon ve Sugeno bulanık mantık modellerinde aynı girdi ve çıktılar kullanılmıştır.

\section{Girdi}

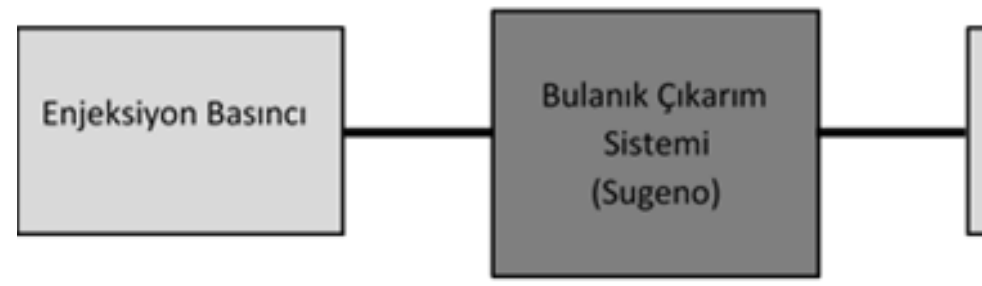

Şekil 6:
C.ktı

Serbest Basınç

Dayanımı

Geliştirilen Sugeno bulanık mantık modelinin şematik gösterimi

Geliştirilen Sugeno bulanık mantık modelinde girdi üyelik fonksiyonu 7 alt kümeden oluşmaktadır (Şekil 7). Her bir üyelik fonksiyonu için dilsel ifadeler (CD: Çok Düşük, D: Düşük, OD: Orta Düşük, O: Orta, OY: Orta Yüksek, Y:Yüksek, CY: Çok Yüksek) tanımlanmıştır.

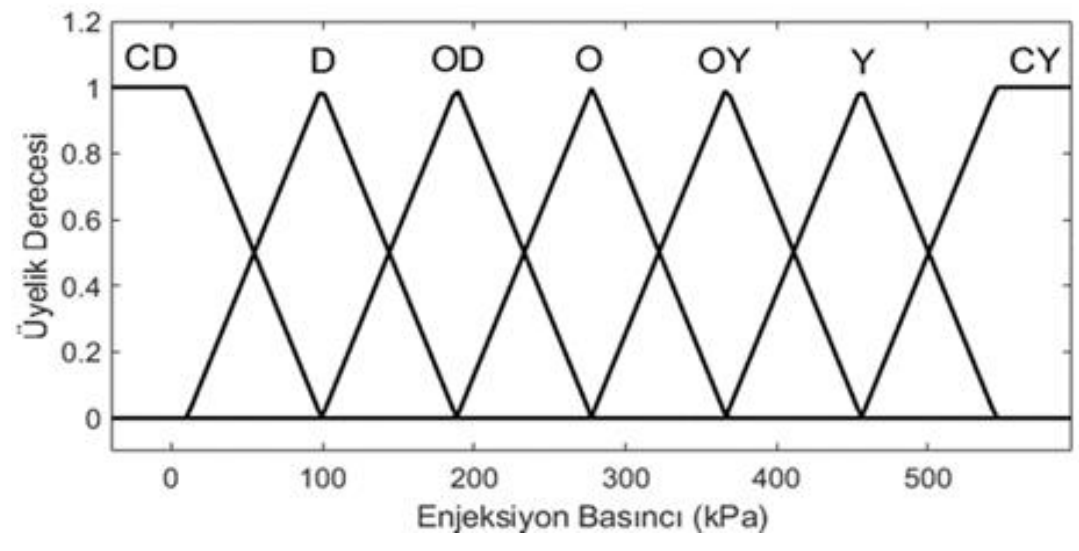

Şekil 7:

Enjeksiyon basıncı parametresi (girdi parametresi) için oluşturulan üyelik fonksiyonları

Sugeno bulanık mantık yönteminde çıktı fonksiyonları sabit (0. derece doğru denklemi) veya doğrusal (1. derece doğru denklemi) olarak seçilmektedir. Bu çalışmada 1. derece denklem seçildiğinden dolayı modelimizi birinci derece Sugeno bulanık mantık olarak nitelendirebiliriz.

Tablo 3'de alt küme sınır değerleri kullanılarak elde edilen doğrusal denklemler ile oluşturulan kural tanımlamaları görülmektedir. Tablo 3'de görüleceği üzere 7 tane kural oluşturulmuştur. Girdi değerlerine ilgili kuralların uygulanması ve Şekil 3'de görülen durulaştırma işlemi sonucunda çıktı değerleri hesaplanmaktadır. Regresyon modelleri ile Sugeno 
BM modelinin tahmin performansını, etkinliğini ve uygulanabilirliğini ölçmek amacıyla ölçülen değerlere karşılık tahmin edilen değerlerin dağılım grafiği çizilmiştir (Şekil 8).

Tablo 3. Enjeksiyon basıncı ile Serbest Basınç Dayanımı arasındaki ilişkiyi içeren Sugeno tipi Bulanık Mantık kuralları

\begin{tabular}{|l|l|}
\hline Kural No & \multicolumn{1}{|c|}{ KURALLAR } \\
\hline 1. Kural & $\begin{array}{l}\text { Eğer Enjeksiyon Basıncı }=\mathrm{CD} \text { ise Serbest Basınç Dayanımı }=0,0329 \\
\text { (Enjeksiyon Basınc1) }+1,0595\end{array}$ \\
\hline 2. Kural & $\begin{array}{l}\text { Eğer Enjeksiyon Basıncı }=\mathrm{D} \text { ise Serbest Basınç Dayanımı }=0,0200 \\
\text { (Enjeksiyon Basınc1) }+3,7711\end{array}$ \\
\hline 3. Kural & $\begin{array}{l}\text { Eğer Enjeksiyon Basıncı }=\text { OD ise Serbest Basınç Dayanımı }=0,0149 \\
\text { (Enjeksiyon Basınc1) }+5,223\end{array}$ \\
\hline 4. Kural & $\begin{array}{l}\text { Eğer Enjeksiyon Basıncı }=\mathrm{D} \text { ise Serbest Basınç Dayanımı }=0,0127 \\
\text { (Enjeksiyon Basınc1) }+7,9395\end{array}$ \\
\hline 5. Kural & $\begin{array}{l}\text { Eğer Enjeksiyon Basıncı }=\mathrm{OY} \text { ise Serbest Basınç Dayanımı }=0,0065 \\
\text { (Enjeksiyon Basınc1) }+13,343\end{array}$ \\
\hline 6. Kural & $\begin{array}{l}\text { Eğer Enjeksiyon Basıncı }=\mathrm{Y} \text { ise Serbest Basınç Dayanımı }=0,013 \\
\text { (Enjeksiyon Basınc1) }+11,942\end{array}$ \\
\hline 7. Kural & $\begin{array}{l}\text { Eğer Enjeksiyon Basıncı }=\mathrm{CY} \text { ise Serbest Basınç Dayanımı }=0,0139 \\
\text { (Enjeksiyon Basınc1) }+15,048\end{array}$ \\
\hline
\end{tabular}

Şekil 8'de görülen dağılımların $\mathrm{R}^{2}$ değerleri, tahmin ve ölçülen değerlerden OKH değerleri hesaplanmıştır. Serbest basınç dayanım değerinin tahmini için oluşturulan beş modelinde oldukça iyi sonuçlar verdiği görülmektedir. Modellerin tahmin ve ölçülen değerleri için elde edilen determinasyon katsayıları; Sugeno BM modeli için 0,8286 , doğrusal regresyon modeli için 0,8259 , polinomal regresyon modeli için 0,8261 , üstel regresyon modeli için 0,8217 ve eksponansiyel regresyon modeli için 0,7973 olarak hesaplanmıştır. OKH değerleri ise Sugeno $\mathrm{BM}$ için 5,8388, doğrusal regresyon modeli için 5,9301, polinomal regresyon modeli için 5,9239, üstel regresyon modeli için 6,0836 ve eksponansiyel regresyon modeli için 6,9043 olarak hesaplanmıştır. Modellerin determinasyon katsayıları ve OKH değerilerine göre en iyi kestirim performansını Sugeno BM modelinin gösterdiği görülmektedir. Bu modeli sırasıyla polinomal, doğrusal, üstel ve eksponansiyel denklemler ile oluşturulan modeller takip etmektedir. Şekil 8'de görüleceği üzere Sugeno BM, doğrusal regresyon modeli, polinom regresyon modeli ve üstel regresyon modeli düşük serbest basınç dayanımı değerlerinde oldukça iyi tahmin başarısı göstermektedir. Buna karşın eksponansiyel regresyon modeli ise daha kötü tahmin başarısı göstermektedir. Yüksek serbest basınç dayanım değerlerinde ise bütün modeller nispeten daha düşük tahmin başarısı göstermektedir. Ölçülen en yüksek serbest basınç dayanım değeri 23,88 MPa'dır. Tahmin edilen en yüksek serbest basınç dayanım değerleri, doğrusal regresyon modeli için 19,35 MPa, polinom regresyon modelinde 19,11 MPa ve üstel regresyon modelinde 18,42 $\mathrm{MPa}$, eksponansiyel regresyon modelinde 22,17 MPa, Sugeno BM ise 22,62 MPa olarak hesaplanmıştır. Şekil 8'de görüleceği üzere yüksek serbest basınç dayanım değerlerinde Sugeno BM modeli daha iyi performans göstermiştir. 
a)

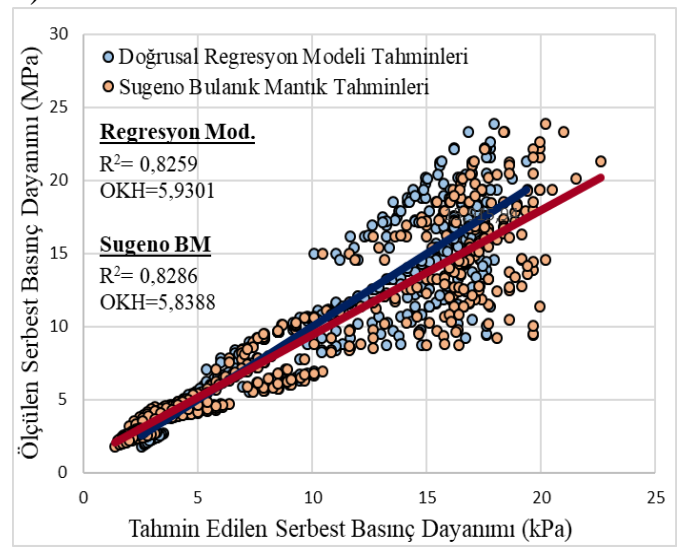

c)

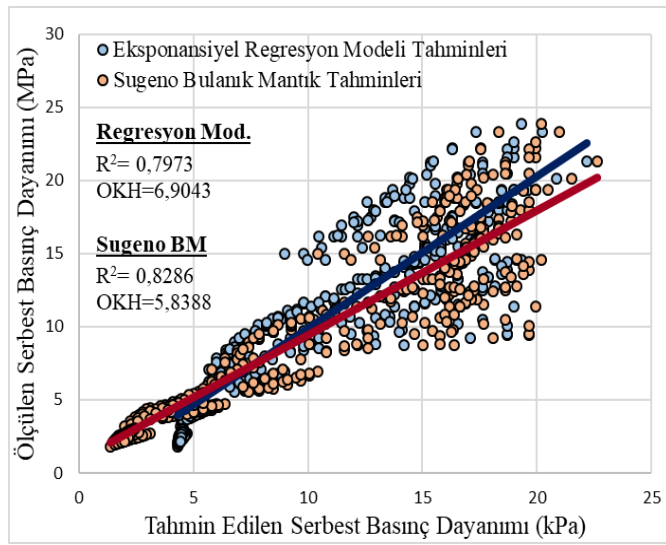

b)

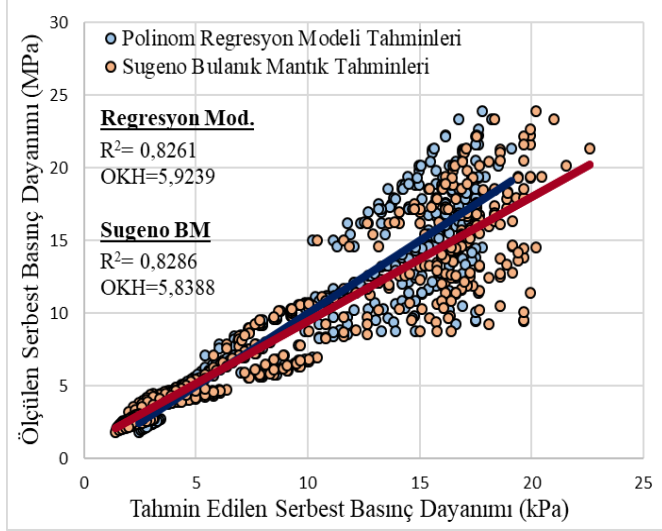

d)

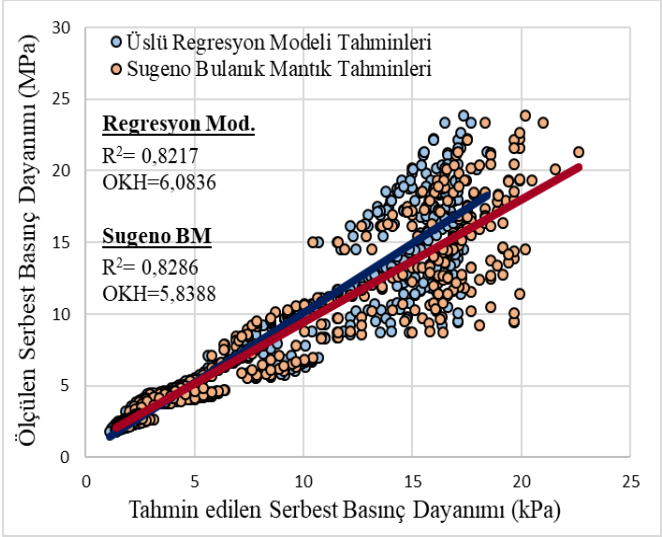

Şekil 8:

Ölçülen ve tahmin edilen Serbest Basınç Dayanım değerleri arasındaki ilişki. a)Doğrusal regresyon modeli ve Sugeno BM modelinin karşılaştırılması, b) Polinom regresyon modeli ve Sugeno BM modelinin karşılaştırılması, c) Eksponansiyel regresyon modeli ve Sugeno BM modelinin karşılaştırılması ve d) Üstel regresyon modeli ve Sugeno BM modelinin karşılaştırılması. Mavi ve kırmızı çizgiler sırasıyla regresyon ve Sugeno BM modelleri için elde edilen regresyon ĕgrilerini göstermektedir.

\section{SONUÇLAR}

$\mathrm{Bu}$ çalışmada serbest basınç dayanım değerinin tahmini amacıyla doğrusal, doğrusal olmayan (polinom, üstel ve eksponansiyel) ve Sugeno BM yöntemleri kullanılarak toplam beş model geliştirilmiştir. Geliştirilen modellerin karşılaştırmaları yapılmış ve Sugeno BM modelinin uygulanabilirliği incelenmiştir. Modellerin tahmin performansının incelenmesi amacıyla $\mathrm{R}^{2}$ değerleri ve OKH değerleri hesaplanmıştır. Çalışmada kullanılan modellerin $\mathrm{R}^{2}$ ve $\mathrm{OKH}$ değerleri birbirlerine oldukça yakındır. Sugeno $\mathrm{BM}$ modelinde elde edilen $\mathrm{R}^{2}$ değeri nispeten daha yüksektir. Bu modeli sırasıyla polinom regresyon modeli, doğrusal regresyon modeli, üstel regresyon modeli ve eksponansiyel regresyon modeli izlemektedir. En düşük OKH değeri Sugeno BM modelinde elde edilmiştir. Bu modeli sırasıyla polinom regresyon modeli, doğrusal regresyon modeli, üstel regresyon modeli ve eksponansiyel regresyon modeli izlemektedir. Tahminde kullanılan modellerin ince taneli çimento ile enjeksiyon yapılmış kum zeminlerin serbest basınç dayanım değerlerini tahmin etmede oldukça iyi sonuçlar verdiği görülmektedir. Geliştirilen tüm modeller karşılaştırıldığında Sugeno BM modeli nispeten daha iyi tahmin performansı gösterdiği 
söylenebilir. Bulanık mantık yaklaşımı klasik mantık sistemini kapsadı̆̆ı ve esnekliğinden dolayı klasik mantık yaklaşımı kullanarak oluşturulan modeller bulanık mantık yöntemi kullanarak da oluşturulabilmektedir. Sugeno bulanık mantık yönteminin insanın düşünme mekanizmasına, çıarım ve karar verme sistemine yakın olmasından dolayı anlaşılması kolaydır. Ayrıca yöntemin esnekliği, uygulama ve kontrolünün kolaylığı, karmaşıklıktan uzak olması, modelleme seçeneklerinin fazla olması gibi önemli avantajları bulunmaktadır. Çalışmada Sugeno BM modeli serbest basınç dayanımının tahmininde oldukça başarılı sonuçlar elde edilmiştir. Sugeno bulanık mantık yönteminin avantajları ve serbest basınç dayanımı tahmin başarısından dolayı regresyon yöntemine alternatif olabileceği görülmüştür.

\section{ÇIKAR ÇATIŞMASI}

Yazarlar, bilinen herhangi bir çıkar çatışması veya herhangi bir kurum/kuruluş ya da kişi ile ortak çıkar bulunmadığını onaylamaktadırlar.

\section{YAZAR KATKISI}

Eray Yıldırım, Eyübhan Avcı ve Bahadır Yılmaz, çalışmanın kavramsal ve tasarım süreçlerinin belirlenmesi ve yönetiminde, veri analizi ve yorumlama, makale taslağının oluşturulması ve fiziksel içeriğin incelenmesi aşamalarında katkı sağlamışlardır. Eyübhan Avcı ayrıca veri toplama aşamasında katkı sağlamıştır. Çalışmanın son onay ve tam sorumluluğunu tüm yazarlar üstlenmektedir.

\section{KAYNAKLAR}

1. Arbabsiar, M.H., Farsangi M.A.E. and Mansouri, H. (2020) Fuzzy logic modelling to predict the level of geotechnical risks in rock Tunnel Boring Machine (TBM) tunneling, Rudarsko Geolosko Naftni Zbornik, 35(2), 1-14. doi:10.17794/rgn.2020.2.1.

2. Avci, E. (2019) Silica Fume Effect on Engineering Properties of Superfine Cement-Grouted Sands, Journal of Materials in Civil Engineering, 31(11), 04019269-1-13, doi:10.1061/(ASCE)MT.1943-5533.0002928.

3. Chen, J., Hagan, P. and Saydam, S. (2018) Shear behaviour of a cement grout tested in the direct shear test, Construction and Building Materials, 166, 271-279. doi:10.1061/(ASCE)MT.1943-5533.0002928.

4. Cho, H.C., Han, S.J., Heo, I, Kang, H., Kang, W.H. and K.S. Kim, K.S. (2020) Heating Temperature Prediction of Concrete Structure Damaged by Fire Using a Bayesian Approach, Sustainability, 12(10), 1-18. doi:10.3390/su12104225.

5. Christodoulou, D., Droudakis, A., Pantazopoulos, I.A., Markou, I. and Atmatzidis, D.K. (2009) Groutability and Effectiveness of Microfine Cement Grouts, Proceedings of the 17th International Conference on Soil Mechanics \& Geotechnical Engineering, vol. 3, Egypt, 2232-2235. doi:10.3233/978-1-60750-031-5-2232. doi:10.3233/978-1-60750-031-5-2232.

6. Dhanasekar, T. and Rajakumar, P. (2018) Effective Utilization of Fuzzy Logic in Stabilize Road Construction with RBI Grade-81, International Journal of Civil Engineering and Technology (IJCIET), 9(1), 41-47. Article ID: IJCIET_09_01_006.

7. Elmas, Ç. (2011) Yapay Zeka Uygulamaları, Seçkin Yayıncılık, Ankara.

8. Hashimoto, K., Nishihara, S. Oji, S., Kanazawa, T., Nishie, S., Seko, I., Hyodo, T. and Tsukamato, Y. (2016) Field testing of permeation grouting using microfine cement, Ground Improvement, 169(2), 134-142, doi:10.1680/jgrim.15.00030. 
9. Jaforpour, P., Moayed, R.Z. and Kordnaeij, A. (2020) Yield stress for zeolite-cement grouted sand, Construction and Building Materials, 247(30), 1-12. doi:10.1016/j.conbuildmat.2020.118639.

10. Karol, R.H. (2003) Chemical Grouting and Soil Stabilization, Marcel Dekker Inc, New Jersey/USA.

11. Mamdani, E.H. and Assilian, S. (1975) An experiment in linguistic synthesis with a fuzzy logic controller", International Journal of Man-Machine Studies, 7(1), 1-13. doi:10.1016/S0020-7373(75)80002-2.

12. Markou I.N. and A. I. Droudakis, A.I. (2013) Shear Strength of Microfine Cement Grouted Sands, Ground Improvement, 166(3), 177-186.

13. Mishra, D.A. and Basu, A. (2013) Estimation of uniaxial compressive strength of rock materials by index tests using regression analysis and fuzzy inference system, Engineering Geology, 160, 54-68. doi:10.1016/j.enggeo.2013.04.004.

14. Nonlevier, E. (1989) Grouting Theory and Practice, Elsevier Science Publishers B.V, Amsterdam/Netherland.

15. Perret, S., Palardy, D. and Ballivy, G. (2000) Rheological Behaviour and Setting Time of Microfine Cement Based Grouts, ACI Materials Journal, 97(4), 472-477.

16. Rawlings, C.G., Hellawell E.E and Kilkenny, W.M. (2000) Grouting for Ground Engineering, Construction Industry Research and Information Association (CIRA), London/UK.

17. Schwarz L.G. and Krizek, R.J. (1994) Effect of preparation technique on permeability and strength of cement-grouted sand, Geotechnical Testing Journal, 17(4), 434-443. doi:10.1520/GTJ10304J.

18. Shroff A.V. and Shah, D.L. (1999) Grouting Technology in Tunneling and Dam Construction, A.A. Balkema, Rotterdam/Netherlands.

19. Sujatha, A., Govindaraju, L. and Shivakumar, N. (2020) Application of Fuzzy Rule Based System For Highway Research Board Classification of Soils, International Journal of Fuzzy Logic Systems (IJFLS), 10(2), 1-14. doi:10.5121/ijfls.2020.10201.

20. Sünbül, A.B., Uzun, R. and Erkaymaz, H. (2015) Zemin sıvılaşma potansiyelinin bulanık mantık ile modellenmesi, Karaelmas Fen ve Mühendislik Dergisi, 5(2), 101-104.

21. Takagi, T. and Sugeno, M. (1985) Fuzzy Identification of Systems and Its Application to Modelling and Control", IEEE Transactions on Systems, Man, and Cybernetics, 15(1), 116132. doi:10.1109/TSMC.1985.6313399.

22. Yıldırım, E., Doğan, E., Karavul, C., Aşçı, M., Özçep, F. and Arman, H. (2007) Classification Of The Soils Using Mamdani - Fuzzy Inference System, International Earthquake Symposium, 578-582, Kocaeli.

23. Yildırım, E., Sertkaya, C. and Karavul, C. (2007) Estimation of Shear Wave Velocity Using Sugeno Fuzzy Logic and Artificial Neural Networks Models, Electronic Letters on Science \& Engineering, 3(1), 1-9.

24. Zadeh, L.A. (1965) Fuzzy sets, Information and Control, 8(3), 338-353.

25. Zorluer, İ., Icaga, Y., Yurtcu, S. and Tosun, H. (2010) Application of a fuzzy rule-based method for the determination of clay dispersibility, Geoderma, 160(2), 189-196. doi:10.1016/j.geoderma.2010.09.017. 